Article

\title{
Quantitative and Chemical Fingerprint Analysis for the Quality Evaluation of Platycodi Radix Collected from Various Regions in China by HPLC Coupled with Chemometrics
}

\author{
Haiyang Lu ${ }^{1}$, Mengzhen Ju ${ }^{1}$, Shanshan Chu ${ }^{1}$, Tao Xu ${ }^{1}$, Yuzhe Huang ${ }^{1}$, Qingyun Chan ${ }^{1}$, \\ Huasheng Peng 1,2,*(D) and Shuangying Gui ${ }^{1,2,3, *}$ \\ 1 College of Pharmacy, Anhui University of Chinese Medicine, Hefei 230012, China; \\ lhy668866@163.com (H.L.); jmz_ahtcm@163.com (M.J.); cshan0916@126.com (S.C.); xutaojy@126.com (T.X.); \\ pfhuangyz@163.com (Y.H.); chanqingyun126@126.com (Q.C.) \\ 2 Synergetic Innovation Center of Anhui Authentic Chinese Medicine Quality Improvement, Hefei 230038, China \\ 3 Institute of Pharmaceutics, Anhui Academy of Chinese Medicine, Hefei 230012, China \\ * Correspondence: hspeng@126.com (H.P.); guishy0520@126.com (S.G.); Tel.: +86-159-0569-2001 (H.P.); \\ $+86-138-5600-2612$ (S.G.)
}

Academic Editor: Derek J. McPhee

Received: 7 June 2018; Accepted: 16 July 2018; Published: 23 July 2018

\begin{abstract}
Platycodi Radix (PR) is the root of Platycodon grandiflorum (Jacq.) A. DC., which has been used for a long time in China to treat pulmonary diseases. The present study aimed to evaluate the quality of PR samples collected from 23 regions of 11 provinces in China. Eight saponins were quantified using HPLC coupled with evaporative light scattering detection (HPLC-ELSD). The samples with the highest total contents of saponins were from southern China, such as Yunnan, Guangxi, Jiangxi, and Guangzhou. The fingerprint analysis of PR samples was conducted by HPLC-UV method. Nineteen common peaks were selected and the similarity values varied from 0.607 to 0.921 . These findings indicated that the saponins contents of PR from different regions varied significantly, with PR samples from southern China having the highest contents of saponins. These comprehensive methods were successful in evaluating the quality of PR samples from northern and southern China, which will serve as a guide for the development of PR as a clinical medication.
\end{abstract}

Keywords: Platycodi Radix; quality evaluation; quantitative analysis; chemical fingerprint analysis; saponin; high performance liquid chromatography (HPLC); chemometrics

\section{Introduction}

Platycodi Radix (PR) is the root of Platycodon grandiflorum (Jacq.) A.DC., which has been used for a long time in China to treat pulmonary diseases. PR is increasingly being used not only as a traditional herbal medicine, but also as a popular functional food due to its rich content of amino acids. It is often made into pickles in Northeast China, Japan, Korea, and other East Asian countries. According to several studies, the starch of PR can be made into high-quality pastry and PR extracts can be used as active ingredients in anti-aging cosmetics and body lotion [1-3]. PR is distributed all over China, from the south to the north. In Chinese books of herbal medicine, PR from eastern China was called "Nan jiegeng" and presumed of better quality, while that distributed in north China and northeast China was called "Bei jiegeng" with larger production. In addition, PR from the south has bitter taste and good quality, according to the ancient book of herbal medicine. PR is an edible plant which can be used as both medicine and food. PR with bitter taste have been usually used as medicine, and that with 
sweet taste have been usually used as food [4]. Chemical compounds that have been isolated from PR include triterpenoid saponins, polysaccharide, flavonoids, phenolic compounds, inorganic elements, steroids, fatty acid, volatile oil, and other bioactive compounds [5-9]. Approximately 20 kinds of platycosides, the main bioactive constituents of PR, are responsible for a variety of biological activities such as anti-inflammation, antitumor, anti-allergy, anti-obesity, antioxidant, and antihyperlipidemic activities [10-13].

Several studies have reported that herbs collected at different times of year, or planted in different geographical environments might differ in quantity of chemical components and quality of medicinal materials [14,15]. Therefore, a comprehensive analysis on the quality control of PR is necessary. High Performance Liquid Chromatography coupled with evaporative light scattering detection (HPLC-ELSD) can detect most compounds regardless of their optical properties, which is effective for simultaneous determination of saponin contents [16,17]. According to Chinese Pharmacopeia (2015), the content of platycoside D in PR should not be less than $0.1 \%$. However, several marker compounds are difficult to evaluate a sample without any information about the other components [18,19]. HPLC fingerprint analysis has been reported to assess the quality of the whole compositions of PR. Chromatographic fingerprint analysis is a useful method for the identification and quality control of botanical medicines [20,21].

The present study aimed to: (1) analyze the variation in saponin profiles of PR collected from 23 regions and 11 provinces in China using hierarchical clustering analysis (HCA) and principal component analysis (PCA) methods; (2) establish an effective HPLC-UV method for the identification and quality evaluation of PR based on HPLC fingerprint analysis; and (3) provide a theoretical basis to classify PR from different regions based on its medicinal quality by chemometrics method.

\section{Results and Discussion}

\subsection{Optimization of Extraction}

The optimization of extraction procedure included the optimization of solvents water, ethanol, methanol, 70\% methanol (methanol/water 70:30,v/v) and extraction times (1, 2 and 3 times). The total contents of eight types of saponins was used as a marker for the evaluation of extraction efficiency. Table 1 shows that 70\% MeOH displayed the highest extraction efficiency, whereas EtOH displayed the lowest. The total contents of saponins increased as the ultrasound duration increased (Table 2).

Table 1. The investigation of different extraction solvents.

\begin{tabular}{cccccccccc}
\hline \multirow{2}{*}{ Solvent Systems } & \multicolumn{8}{c}{ The Contents of Each Compound $\left.{ }^{\mathbf{a}} \mathbf{( m g} / \mathbf{g}\right)$} \\
\cline { 2 - 10 } & $\mathbf{1}$ & $\mathbf{2}$ & $\mathbf{3}$ & $\mathbf{4}$ & $\mathbf{5}$ & $\mathbf{6}$ & $\mathbf{7}$ & $\mathbf{8}$ \\
\hline Water & 0.949 & 1.924 & 0.481 & 1.225 & 0.698 & 0.165 & 3.506 & 0.963 \\
MeOH & 0.931 & 1.846 & 0.534 & 1.596 & 0.564 & 0.178 & 3.501 & 1.675 \\
$70 \% \mathrm{MeOH}$ & 1.501 & 2.882 & 0.860 & 2.525 & 0.936 & 0.233 & 5.390 & 2.017 \\
EtOH & 0.181 & 0.396 & 0.192 & 0.413 & 0.232 & $-\mathrm{b}$ & 1.546 & 0.927 \\
\hline
\end{tabular}

a (1) Deapioplatycoside E; (2) Platycoside E; (3) Deapioplatycodin $\mathrm{D}_{3}$; (4) Platycodin $\mathrm{D}_{3}$; (5) Deapioplatycodin D; (6) Platycodin $\mathrm{D}_{2}$; (7) Platycodin $\mathrm{D}$; (8) Polygalacin $\mathrm{D}$; ${ }^{\mathrm{b}}$ undetected.

Table 2. The investigation of different extraction times.

\begin{tabular}{ccccccccc}
\hline \multirow{2}{*}{ Extraction Times } & \multicolumn{7}{c}{ The Content of Each Compound a $\left.^{\mathbf{a}} \mathbf{( m g} / \mathbf{g}\right)$} \\
\cline { 2 - 10 } & $\mathbf{1}$ & $\mathbf{2}$ & $\mathbf{3}$ & $\mathbf{4}$ & $\mathbf{5}$ & $\mathbf{6}$ & $\mathbf{7}$ & $\mathbf{8}$ \\
\hline One & 1.342 & 2.629 & 0.614 & 2.016 & 0.830 & $-\mathrm{b}$ & 4.852 & 1.755 \\
Two & 1.655 & 3.170 & 0.963 & 2.545 & 1.061 & 0.314 & 6.079 & 2.165 \\
Three & 1.739 & 3.355 & 1.043 & 2.739 & 1.062 & 0.262 & 6.264 & 2.189 \\
\hline
\end{tabular}

a (1) Deapioplatycoside E; (2) Platycoside E; (3) Deapioplatycodin $\mathrm{D}_{3}$; (4) Platycodin $\mathrm{D}_{3}$; (5) Deapioplatycodin D; (6) Platycodin $\mathrm{D}_{2}$; (7) Platycodin $\mathrm{D}$; (8) Polygalacin D. ${ }^{\mathrm{b}}$ undetected. 


\subsection{Method Validation}

A developed HPLC-ELSD method was used to assess the repeatability, precision, recovery, stability, and linear ranges of method to determine contents of eight saponins. The results indicated a positive correlation between the natural logarithm of the investigated compounds' mass and that of their peak areas within the test ranges $\left(R^{2}>0.9974\right)$ (Table 3$)$. The precision (RSD) value of the method was less than $2.84 \%$. The stability and repeatability (RSD) values were both less than $2.94 \%$. The method recovery (RSD) value was less than $2.59 \%$ (Table 4 ). The results showed that the method was precise and accurate for the quantitative determination of eight saponins contents in PR from different regions.

Table 3. The results of the regression equation, $\mathrm{R}^{2}$ and linearity range of eight saponins.

\begin{tabular}{cccc}
\hline Compound $^{\mathbf{a}}$ & Regression Equation & $\mathbf{R}^{\mathbf{2}}$ & Linearity Range( $\boldsymbol{\mu g})$ \\
\hline $\mathbf{1}$ & $\mathrm{y}=1.4275 \mathrm{x}+6.0015$ & 0.9974 & $1.290 \sim 12.900$ \\
$\mathbf{2}$ & $\mathrm{y}=1.448 \mathrm{x}+5.7217$ & 0.9977 & $1.500 \sim 15.000$ \\
$\mathbf{3}$ & $\mathrm{y}=1.5908 \mathrm{x}+5.6015$ & 0.9978 & $0.690 \sim 6.900$ \\
$\mathbf{4}$ & $\mathrm{y}=1.556 \mathrm{x}+5.3293$ & 0.9975 & $1.131 \sim 11.310$ \\
$\mathbf{5}$ & $\mathrm{y}=1.6544 \mathrm{x}+5.3848$ & 0.9982 & $0.534 \sim 5.340$ \\
$\mathbf{6}$ & $\mathrm{y}=1.6606 \mathrm{x}+5.1075$ & 0.9976 & $0.630 \sim 6.300$ \\
$\mathbf{7}$ & $\mathrm{y}=1.464 \mathrm{x}+5.0489$ & 0.9999 & $2.400 \sim 24.000$ \\
$\mathbf{8}$ & $\mathrm{y}=1.6435 \mathrm{x}+4.9158$ & 0.9989 & $1.095 \sim 10.950$ \\
\hline
\end{tabular}

a (1) Deapioplatycoside E; (2) Platycoside E; (3) Deapioplatycodin $\mathrm{D}_{3}$; (4) Platycodin $\mathrm{D}_{3}$; (5) Deapioplatycodin D; (6) Platycodin $\mathrm{D}_{2}$; (7) Platycodin D; (8) Polygalacin D.

Table 4. The results of the precision, stability, repeatability, and recovery tests.

\begin{tabular}{ccccc}
\hline Compound $^{\text {a }}$ & Precision (RSD, \%) & Stability (RSD, \%) & Repeatability (RSD, \%) & Recovery (RSD, \%) \\
\hline $\mathbf{1}$ & 0.65 & 2.73 & 1.07 & 1.89 \\
$\mathbf{2}$ & 1.00 & 2.85 & 1.65 & 1.52 \\
$\mathbf{3}$ & 2.55 & 0.97 & 1.22 & 1.86 \\
$\mathbf{4}$ & 0.72 & 1.71 & 2.94 & 1.93 \\
$\mathbf{5}$ & 2.79 & 1.82 & 1.48 & 2.13 \\
$\mathbf{6}$ & 1.80 & 2.48 & 2.70 & 2.59 \\
$\mathbf{7}$ & 1.57 & 1.02 & 1.21 & 1.54 \\
$\mathbf{8}$ & 2.84 & 2.94 & 1.84 & 1.37 \\
\hline
\end{tabular}

a (1) Deapioplatycoside E; (2) Platycoside E; (3) Deapioplatycodin $\mathrm{D}_{3}$; (4) Platycodin $\mathrm{D}_{3}$; (5) Deapioplatycodin D;

(6) Platycodin $\mathrm{D}_{2}$; (7) Platycodin D; (8) Polygalacin D. RSD = relative standard deviation.

\subsection{Quality Evaluation of PR in China}

\subsubsection{Quantification of Eight Investigated Compounds in PR}

The developed HPLC-ELSD method was applied for the quantitative determination of 8 types of saponins in 89 PR samples. The saponins in PR samples were well separated using the developed HPLC method based on the comparison of their retention time with the reference substances. Peaks 1, 2, 3, 4, 5, 6, 7, and 8 were identified as deapioplatycoside E, platycoside E, deapioplatycodin $D_{3}$, platycodin $\mathrm{D}_{3}$, deapioplatycodin $\mathrm{D}$, platycodin $\mathrm{D}_{2}$, platycodin $\mathrm{D}$, and polygalacin $\mathrm{D}$, respectively (Figure 1). The contents of the eight types of saponins in PR samples collected from 23 regions in China are summarized in Supplementary Table S1. 

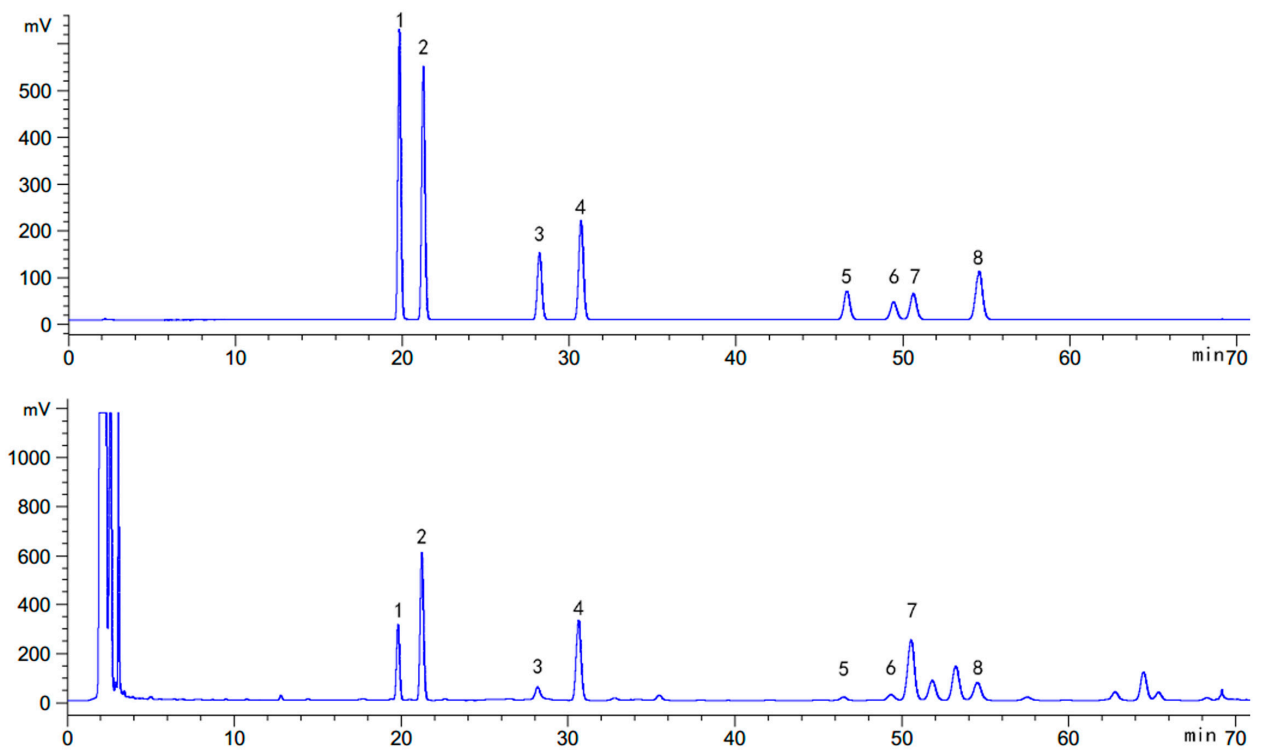

Figure 1. Peaks identification: (1) Deapioplatycoside E; (2) Platycoside E; (3) Deapioplatycodin $\mathrm{D}_{3}$; (4) Platycodin $\mathrm{D}_{3}$; (5) Deapioplatycodin D; (6) Platycodin $\mathrm{D}_{2}$; (7) Platycodin D; (8) Polygalacin D.

As shown in Supplementary Table S1, there was a large difference in the contents of the eight saponins from all samples. Deapioplatycoside E contents ranged from 0.092 to $2.772 \mathrm{mg} / \mathrm{g}$, whereas platycoside E contents were within a range of $0.335-4.291 \mathrm{mg} / \mathrm{g}$. Deapioplatycodin $\mathrm{D}_{3}$ contents in most samples were lower than $1 \mathrm{mg} / \mathrm{g}$. Platycodin $\mathrm{D}_{3}$ contents were within a range of $0.282-5.650 \mathrm{mg} / \mathrm{g}$. Deapioplatycodin D and platycodin $\mathrm{D}_{2}$ contents were lower than $1.623 \mathrm{mg} / \mathrm{g}$ and $1.355 \mathrm{mg} / \mathrm{g}$, respectively. The contents of platycodin D ranged from 0.234 to $6.822 \mathrm{mg} / \mathrm{g}$, whereas polygalacin D contents were within a range of $0.195-2.171 \mathrm{mg} / \mathrm{g}$. Thus, the compounds with higher concentration in the samples were deapioplatycoside $\mathrm{E}$, platycoside $\mathrm{E}$, platycodin $\mathrm{D}_{3}$, platycodin $\mathrm{D}$, and polygalacin $\mathrm{D}$.

Due to individual differences of each sample, it was difficult to exactly determine the quality of PR from the 11 provinces. To evaluate the quality of samples, the average contents of all were selected (Table 5, Figure 2).

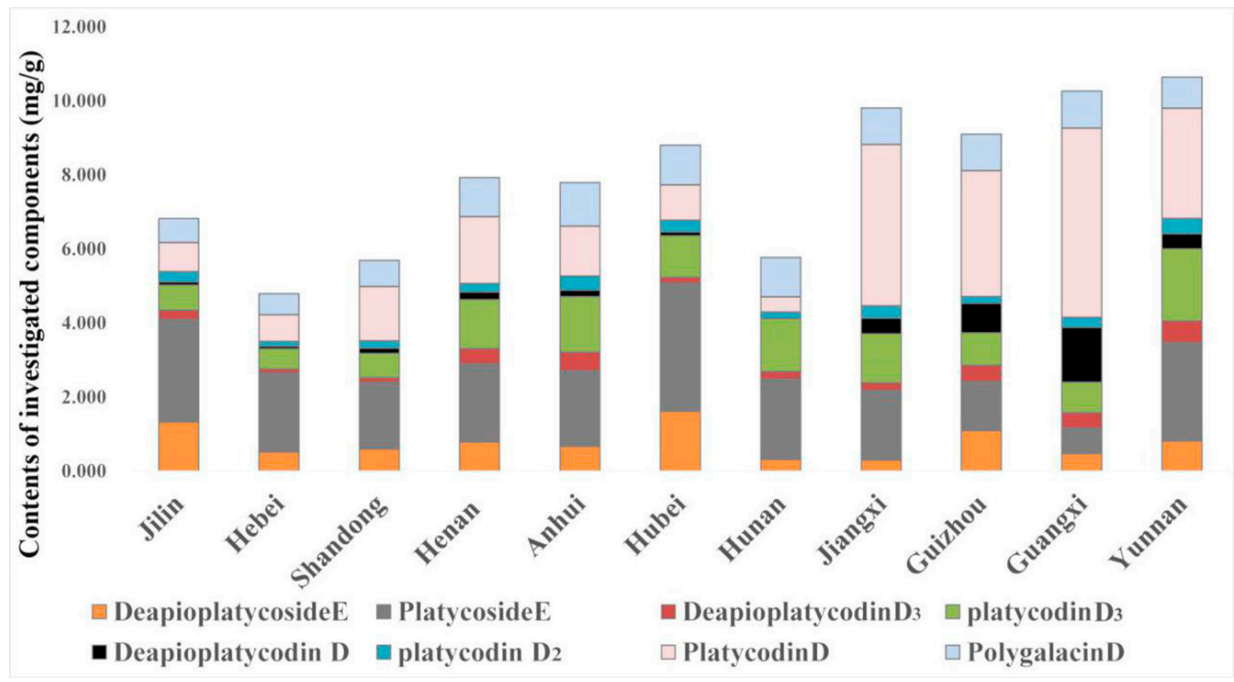

Figure 2. Comparison of eight investigated compounds in samples from 11 provinces. 
Table 5. Contents (mg/g) of eight investigated compounds in samples from 11 provinces.

\begin{tabular}{|c|c|c|c|c|c|c|c|c|c|c|}
\hline \multirow{2}{*}{ Code } & \multirow{2}{*}{ Province } & \multicolumn{8}{|c|}{ The Average Contents of each Compound a (mg/g) } & \multirow{2}{*}{ Total } \\
\hline & & 1 & 2 & 3 & 4 & 5 & 6 & 7 & 8 & \\
\hline P1 & Jilin & $1.324 \pm 0.735$ & $2.774 \pm 0.707$ & $0.247 \pm 0.135$ & $0.682 \pm 0.299$ & $0.081 \pm 0.091$ & $0.278 \pm 0.149$ & $0.787 \pm 0.494$ & $0.651 \pm 0.227$ & 6.824 \\
\hline $\mathrm{P} 2$ & Hebei & $0.516 \pm 0.228$ & $2.133 \pm 0.963$ & $0.103 \pm 0.070$ & $0.559 \pm 0.161$ & $0.064 \pm 0.055$ & $0.129 \pm 0.083$ & $0.717 \pm 0.307$ & $0.571 \pm 0.629$ & 4.792 \\
\hline P3 & Shandong & $0.593 \pm 0.440$ & $1.796 \pm 0.362$ & $0.134 \pm 0.109$ & $0.656 \pm 0.261$ & $0.137 \pm 0.161$ & $0.198 \pm 0.149$ & $1.469 \pm 1.011$ & $0.709 \pm 0.245$ & 5.692 \\
\hline $\mathrm{P} 4$ & Henan & $0.788 \pm 0.469$ & $2.103 \pm 0.786$ & $0.419 \pm 0.272$ & $1.323 \pm 0.570$ & $0.200 \pm 0.235$ & $0.232 \pm 0.149$ & $1.807 \pm 1.293$ & $1.060 \pm 0.472$ & 7.932 \\
\hline P5 & Anhui & $0.669 \pm 0.568$ & $2.040 \pm 0.985$ & $0.505 \pm 0.854$ & $1.501 \pm 1.264$ & $0.169 \pm 0.314$ & $0.381 \pm 0.362$ & $1.351 \pm 1.101$ & $1.180 \pm 0.610$ & 7.796 \\
\hline P6 & Hubei & $1.616 \pm 0.890$ & $3.462 \pm 0.977$ & $0.156 \pm 0.016$ & $1.122 \pm 0.330$ & $0.103 \pm 0.035$ & $0.318 \pm 0.082$ & $0.954 \pm 0.277$ & $1.080 \pm 0.078$ & 8.811 \\
\hline P7 & Hunan & $0.313 \pm 0.022$ & $2.172 \pm 0.553$ & $0.209 \pm 0.009$ & $1.428 \pm 0.638$ & $-b$ & $0.177 \pm 0.008$ & $0.409 \pm 0.110$ & $1.070 \pm 0.342$ & 5.778 \\
\hline P8 & Jiangxi & $0.296 \pm 0.083$ & $1.883 \pm 0.512$ & $0.207 \pm 0.009$ & $1.323 \pm 0.525$ & $0.418 \pm 0.182$ & $0.335 \pm 0.058$ & $4.362 \pm 1.667$ & $0.992 \pm 0.353$ & 9.816 \\
\hline P9 & Guizhou & $1.096 \pm 0.763$ & $1.321 \pm 0.713$ & $0.439 \pm 0.269$ & $0.880 \pm 0.324$ & $0.795 \pm 0.381$ & $0.185 \pm 0.044$ & $3.402 \pm 0.973$ & $0.988 \pm 0.248$ & 9.106 \\
\hline P10 & Guangxi & $0.473 \pm 0.338$ & $0.691 \pm 0.374$ & $0.413 \pm 0.083$ & $0.827 \pm 0.242$ & $1.477 \pm 0.146$ & $0.269 \pm 0.088$ & $5.113 \pm 0.905$ & $1.006 \pm 0.213$ & 10.269 \\
\hline P11 & Yunnan & $0.810 \pm 0.411$ & $2.656 \pm 1.172$ & $0.592 \pm 0.261$ & $1.951 \pm 0.489$ & $0.399 \pm 0.100$ & $0.418 \pm 0.056$ & $2.978 \pm 0.751$ & $0.843 \pm 0.057$ & 10.647 \\
\hline
\end{tabular}

a (1) Deapioplatycoside E; (2) Platycoside E; (3) Deapioplatycodin $\mathrm{D}_{3}$; (4) Platycodin $\mathrm{D}_{3}$; (5) Deapioplatycodin D; (6) Platycodin $\mathrm{D}_{2}$; (7) Platycodin D; (8) Polygalacin D. ${ }^{\mathrm{b}}$ undetected. 
The results showed that saponins contents in PR from the different regions greatly varied, as shown in Table 5 and Figure 2. According to Chinese Pharmacopeia (2015), the content of platycoside $\mathrm{D}$ in PR should not be less than $0.1 \%$. The content of platycodon $\mathrm{D}$ in samples from four provinces (Jilin, Hebei, Hubei, Hunan) did not reach this criterion. The samples with the lowest total contents of the eight saponins were from Hebei $(4.792 \mathrm{mg} / \mathrm{g})$, followed by samples from Shandong (5.692 mg/g), Hunan $(5.778 \mathrm{mg} / \mathrm{g})$, and Jilin $(6.824 \mathrm{mg} / \mathrm{g})$, whereas the samples with the highest total contents of the eight saponins were from Yunnan $(10.647 \mathrm{mg} / \mathrm{g})$, followed by samples from Guangxi (10.269 mg/g), Jiangxi (9.816 mg/g), and Guangzhou $(9.106 \mathrm{mg} / \mathrm{g})$. The four PR samples with higher contents of saponin were considered of higher quality. The most abundant types of saponins in the PR samples, namely deapioplatycoside $E$, platycoside $E$, platycodin $\mathrm{D}_{3}$, platycodin $\mathrm{D}$, and polygalacin $\mathrm{D}$, could be the main ingredients of PR and might be suitable for quality evaluation of PR.

\subsubsection{Hierarchical Clustering Analysis (HCA)}

HCA of the samples from 11 provinces was performed based on their eight saponins contents. Figure 3 clearly shows that the 11 provinces could be divided into four clusters: Hebei, Shandong, and Jilin, with the lowest total contents of eight saponins, were classified into one cluster (Cluster I). The geographical locations of these provinces reflected the low quality of the samples from these regions. Jiangxi, Guizhou, Guangxi, and Yunnan, with the highest total contents of eight saponins, were classified into cluster III and IV, indicating the high quality of the samples from these provinces.

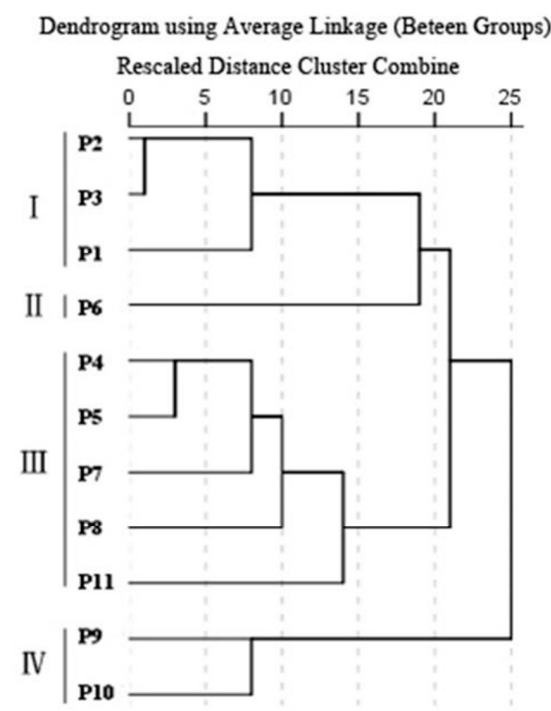

A

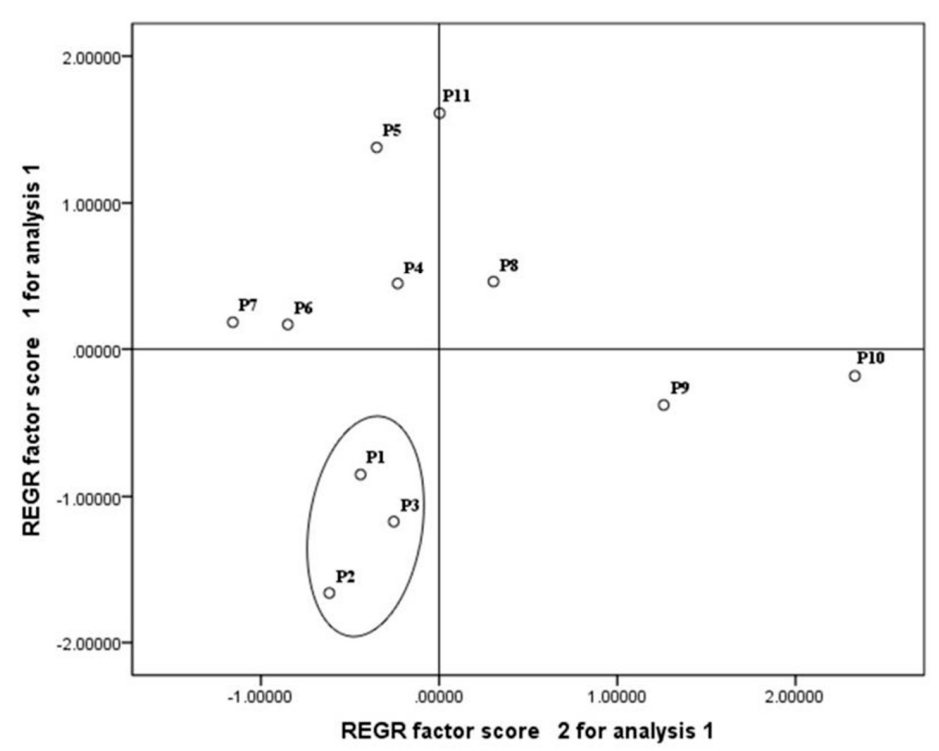

$\mathrm{B}$

Figure 3. Results of hierarchical cluster analysis and principal component analysis of the samples from 11 provinces. (A: hierarchical cluster analysis; B: principal component analysis).

\subsubsection{Principal Component Analysis (PCA)}

In order to evaluate the homogeneity of the quality of PR samples from the different regions of China, PCA was performed. The scatter points (Figure 3) showed that the results were consistent with that of HCA, in which the samples from Jilin, Hebei, and Shandong were distributed together, suggesting the homogeneity of PR quality from these regions, which was low due to their low contents of saponins. Obviously, these provinces could be distinguished from the other regions through the scatter diagram. Therefore, the eight saponins contents of PR have a potential use as markers for the quality assessment of PR. 


\subsection{Establishment of Chromatographic Fingerprint of PR and Similarity Analysis (SA)}

To standardize the HPLC profile, the samples of each origin were analyzed, and all chromatograms were referred to the "Similarity Evaluation System for Chromatographic Fingerprint of Traditional Chinese Medicine" (Version 2004A, Chinese Pharmacopoeia Commission, Beijing, China). The chromatographic fingerprint of PR from 23 locations was shown in Figure 4B, in which there were 19 distinct common peaks with clear separations from the common patterns in the 23 samples of each origin. Five common peaks (peak 7,8,10,11, and 14) were identified as deapioplatycoside E, platycoside $\mathrm{E}$, platycodin $\mathrm{D}_{3}$, platycodin $\mathrm{D}$, and polygalacin $\mathrm{D}$, respectively by comparing their retention time with the reference substances (Figure $4 \mathrm{~A}$ ). Low contents of deapioplatycodin $\mathrm{D}_{3}$ (peak P1), deapioplatycodin D (peak P2), and platycodin $\mathrm{D}_{2}$ (peak P3) were not shown in the chromatographic fingerprint.

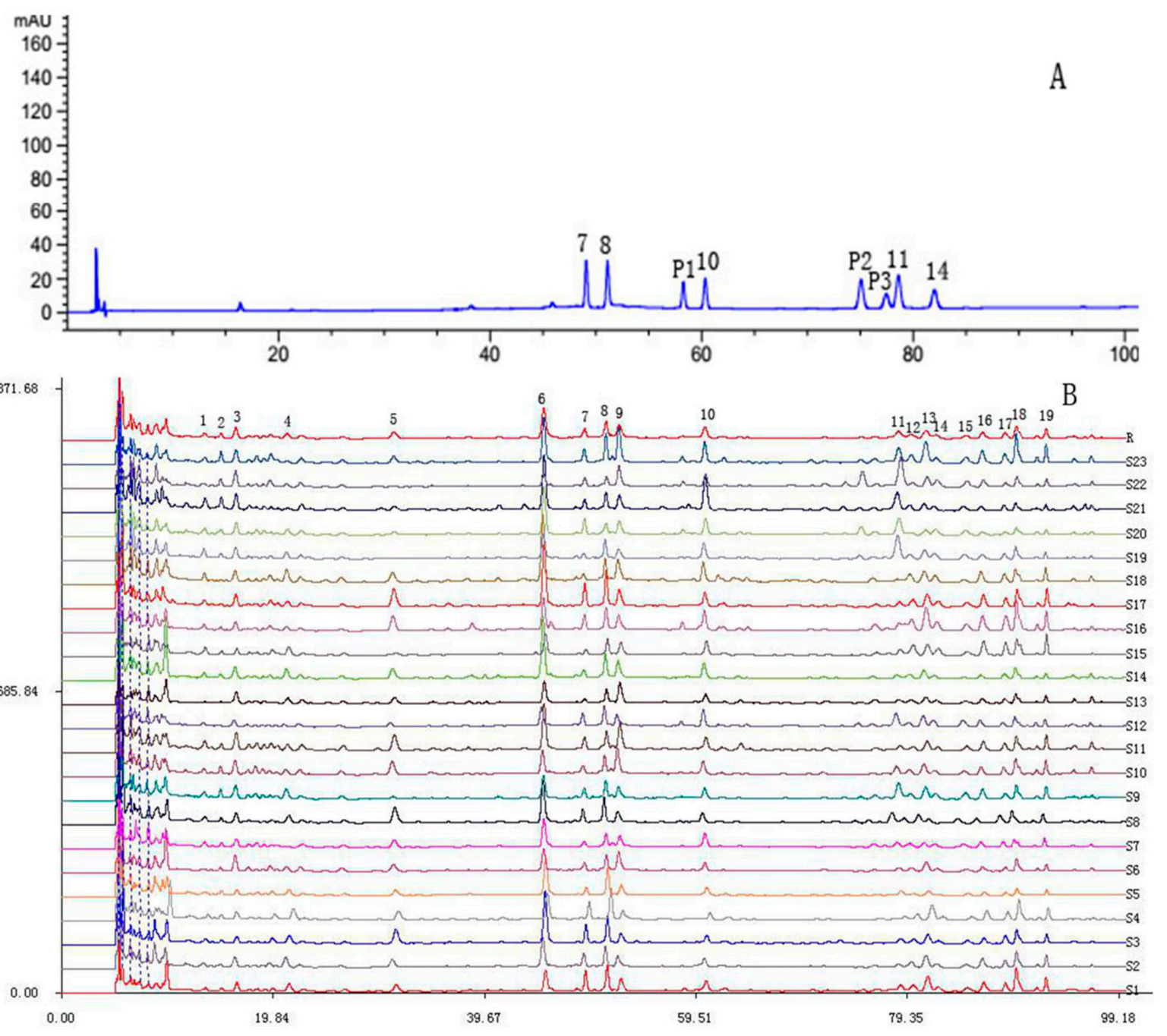

Figure 4. (A): 7 Deapioplatycoside E; 8 Platycoside E; P1 Deapioplatycodin $\mathrm{D}_{3} ; 10$ Platycodin $\mathrm{D}_{3}$; P2 Deapioplatycodin D; P3 Platycodin $\mathrm{D}_{2} ; 11$ Platycodin D; 14 Polygalacin D; (B): The chromatographic fingerprint of PR from 23 locations.

The comparison between the standard fingerprint of the different samples showed similarity values ranged from 0.607 to 0.921 (Table 6). The samples S3, S5, and S15 have similarity values of less than 0.631 , whereas the other samples have similarity values of more than 0.749 . The results indicated the composition and content of chemical compounds in the PR of 23 locations varied significantly. 
Table 6. The similarities of the chromatograms of PR from each location.

\begin{tabular}{cccc}
\hline Samples & Similarities & Samples & Similarities \\
\hline S1 & 0.873 & S13 & 0.900 \\
S2 & 0.775 & S14 & 0.888 \\
S3 & $\mathbf{0 . 6 3 1}$ & S15 & $\mathbf{0 . 6 0 7}$ \\
S4 & 0.769 & S16 & 0.876 \\
S5 & 0.610 & S17 & 0.879 \\
S6 & 0.879 & S18 & 0.887 \\
S7 & 0.895 & S19 & 0.875 \\
S8 & 0.916 & S20 & 0.902 \\
S9 & 0.793 & S21 & 0.872 \\
S10 & 0.837 & S22 & 0.749 \\
S11 & 0.919 & S23 & 0.921 \\
S12 & 0.838 & & \\
\hline
\end{tabular}

\section{Materials and Methods}

\subsection{Samples and Reagents}

Wild PR samples were collected from 23 regions in 11 different provinces in China during September-October (Table 7, Figure 5). The growth years of all samples were determined by the bowl-shaped stem marks (known as "Luwan" in Chinese), and some samples showed clear growth rings after phloroglucinol staining method [22] (Figure 6). PR samples were authenticated as the root of Platycodon grandiflorum by Professor Huasheng Peng and deposited to Synergetic Innovation Center of Anhui Authentic Chinese Medicine Quality Improvement, Anhui University of Chinese Medicine, Hefei, China.

Table 7. PR samples collected from different regions of China.

\begin{tabular}{|c|c|c|c|c|}
\hline NO. & Origin & Coordinates & Number of samples & Code \\
\hline S1 & Lalahe, Dongfeng, Jilin & $\mathrm{N} 42^{\circ} 39^{\prime}$ E $125^{\circ} 23^{\prime}$ & 5 & JL1-1 JL1-5 \\
\hline $\mathrm{S} 2$ & Hengdaohe, Dongfeng, Jilin & $\mathrm{N} 42^{\circ} 24^{\prime} \mathrm{E} 125^{\circ} 17^{\prime}$ & 6 & JL2-1 JL2-6 \\
\hline S3 & Xiaoyang, Meihekou, Jilin & $\mathrm{N} 42^{\circ} 18^{\prime}$ E $125^{\circ} 24^{\prime}$ & 4 & JL3-1 JL3-4 \\
\hline S4 & Shuidao, Meihekou, Jilin & $\mathrm{N} 42^{\circ} 18^{\prime} \mathrm{E} 125^{\circ} 32^{\prime}$ & 4 & JL4-1 JL4-4 \\
\hline S5 & Cangyan mountain, Jingxing, Hebei & $\mathrm{N} 37^{\circ} 50^{\prime} \mathrm{E} 114^{\circ} 07^{\prime}$ & 4 & HeB1-1 HeB1-4 \\
\hline S6 & Qingta, she, Hebei & $\mathrm{N} 36^{\circ} 47^{\prime}$ E $113^{\circ} 45^{\prime}$ & 4 & HeB2-1 HeB2-4 \\
\hline S7 & Culai mountain, Taian, Shandong & N $36^{\circ} 06^{\prime}$ E $117^{\circ} 16^{\prime}$ & 4 & SD1-1 SD1-4 \\
\hline S8 & Chishang, Zibo, Shandong & $\mathrm{N} 36^{\circ} 21^{\prime} \mathrm{E} 118^{\circ} 04^{\prime}$ & 5 & SD2-1 SD2-5 \\
\hline S9 & Longquan, Yantai, Shandong & $\mathrm{N} 37^{\circ} 20^{\prime}$ E $121^{\circ} 47^{\prime}$ & 3 & SD3-1 SD3-3 \\
\hline S10 & Chengiiao, Tongbai, Henan & $\mathrm{N} 32^{\circ} 22^{\prime} \mathrm{E} 113^{\circ} 23^{\prime}$ & 3 & HeN1-1 HeN1-3 \\
\hline S11 & Laowan, Tongbai, Henan & $\mathrm{N} 32^{\circ} 27^{\prime}$ E $113^{\circ} 19^{\prime}$ & 4 & HeN2-1 HeN2-4 \\
\hline $\mathrm{S} 12$ & Guxian, Tongbai, Henan & $\mathrm{N} 32^{\circ} 25^{\prime}$ E $113^{\circ} 37^{\prime}$ & 5 & HeN3-1 HeN3 5 \\
\hline S13 & Taohuatan, Jing, Anhui & $\mathrm{N} 30^{\circ} 31^{\prime} \mathrm{E} 118^{\circ} 11^{\prime}$ & 4 & AH1-1 AH1-4 \\
\hline S14 & Langya mountain, Chuzhou, Anhui & N $32^{\circ} 16^{\prime}$ E $118^{\circ} 16^{\prime}$ & 5 & AH2-1-AH2-5 \\
\hline S15 & Jinzhai, Anhui & N $31^{\circ} 43^{\prime}$ E $115^{\circ} 55^{\prime}$ & 1 & AH3-1 \\
\hline S16 & Tongcheng, Anhui & $\mathrm{N} 31^{\circ} 02^{\prime} \mathrm{E} 116^{\circ} 55^{\prime}$ & 5 & $\mathrm{AH} 4-1 \sim \mathrm{AH} 4 \sim 5$ \\
\hline S17 & Zhang mountain, Hong'an, Hubei & $\mathrm{N} 31^{\circ} 14^{\prime}$ E $114^{\circ} 38^{\prime}$ & 4 & HuB1 HuB4 \\
\hline S18 & Anren, Hunan & N $26^{\circ} 42^{\prime}$ E $113^{\circ} 15^{\prime}$ & 2 & HuN1, HuN2 \\
\hline S19 & Tianpu, Wuning, Jiangxi & $\mathrm{N} 29^{\circ} 27^{\prime} \mathrm{E} 115^{\circ} 11^{\prime}$ & 4 & JX1 JX4 \\
\hline S20 & Pingyang, Rongjiang, Guizhou & $\mathrm{N} 26^{\circ} 17^{\prime}$ E $108^{\circ} 20^{\prime}$ & 4 & GZ1-1 GZ1 4 \\
\hline S21 & Caotang, weng'an, Guizhou & $\mathrm{N} 27^{\circ} 10^{\prime}$ E $107^{\circ} 33^{\prime}$ & 2 & GZ2-1, GZ2 2 \\
\hline S22 & Lingui, Guangxi & $\mathrm{N} 25^{\circ} 14^{\prime} \mathrm{E} 110^{\circ} 12^{\prime}$ & 3 & $\mathrm{GX1} \mathrm{GX} 3$ \\
\hline $\mathrm{S} 23$ & Liancheng, Guangnan, Yunnan & $\mathrm{N} 24^{\circ} 03^{\prime}$ E $105^{\circ} 01^{\prime}$ & 4 & YN1 YN4 \\
\hline
\end{tabular}




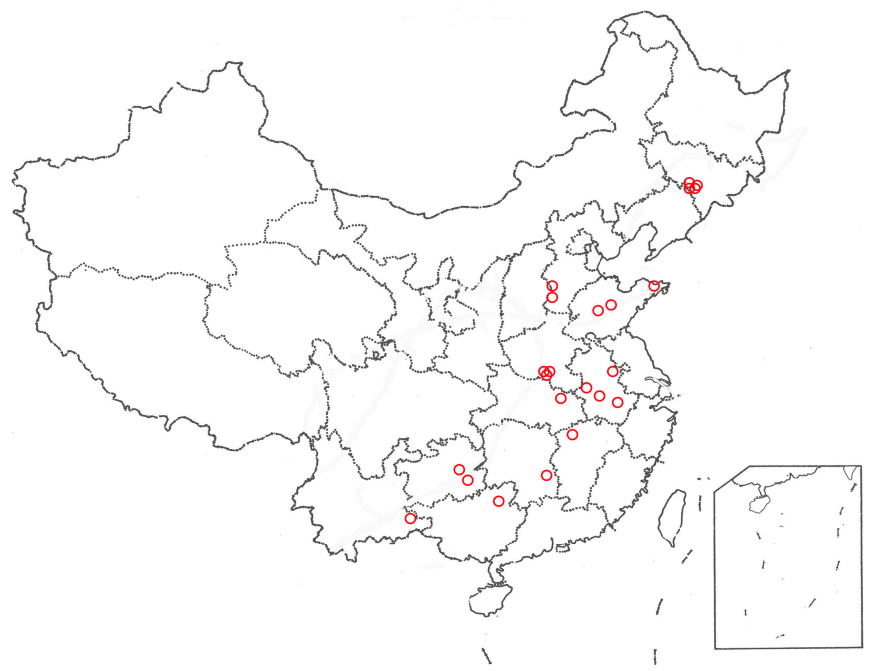

Figure 5. PR sampling locations in different regions in China.

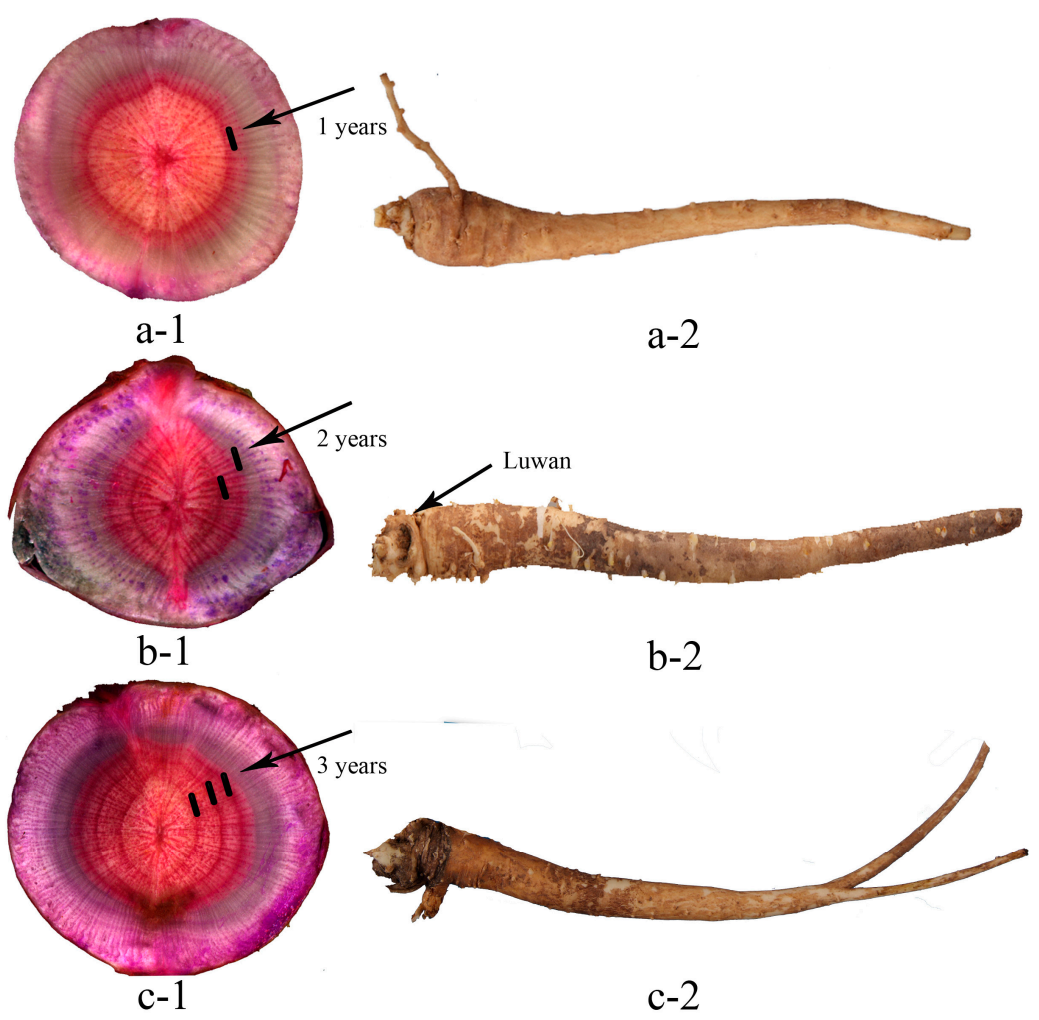

Figure 6. The determination of growth years of PR samples (1. transverse section of root; 2. root; a. one-year root; b. two-years root; c. three-years root.).

HPLC-grade acetonitrile was purchased from Sinopharm Chemical Reagent Co., Ltd. (Shanghai, China). HPLC-grade water was prepared using a Milli-Q water purification system from Pall Filter Co., Ltd. (Beijing, China). All other reagents were of analytical grade. Platycoside E, deapioplatycoside E, platycodin $\mathrm{D}_{3}$, and deapioplatycodin $\mathrm{D}_{3}$ were purchased from Chengdu Push Biotechnology Co., Ltd. (Chengdu, China). Platycodin D was purchased from Chengdu Must Bio-Technology Co., Ltd. (Chengdu, China). Deapioplatycodin $\mathrm{D}$, platycodin $\mathrm{D}_{2}$, and polygalacin $\mathrm{D}$ were purchased from Chengdu Biopurify Phytochemicals, Ltd. (Chengdu, China). The purity of the all saponins was higher than $98 \%$. 


\subsection{Sample Preparation}

PR samples were vacuum-dried in an oven (Type DZF-6050, Shanghai Boxun Industry and Commerce Co., Ltd., Shanghai, China) at $50{ }^{\circ} \mathrm{C}$ and were ground into fine powder (50 mesh) using a powdering machine (Type RHP-250A, Zhejiang Yongkang Ronghao Industy Trade Co., Ltd., Yongkang, China). Subsequently, different extraction solvents (methanol, 70\% methanol, ethanol, water) and extraction times (1,2, and 3 times) were evaluated for the optimization of PR extract (Tables 1 and 2). PR power ( $1.5 \mathrm{~g}$ ) was extracted thrice with $30 \mathrm{~mL}$ of $70 \%$ methanol by ultrasonic at $25{ }^{\circ} \mathrm{C}$ for $30 \mathrm{~min}$. The extract was filtered and evaporated. The resulting residue was dissolved in $10 \mathrm{~mL} \mathrm{50 \%} \mathrm{methanol} \mathrm{(methanol/water} \mathrm{50:50,} / \mathrm{v}$ ) solution, and then filtered through a $0.45 \mu \mathrm{m}$ Nylon filter prior to HPLC analysis with an injection volume of $30 \mu \mathrm{L}$.

\subsection{HPLC-ELSD Instrumentation and Chromatographic Conditions}

All analyses were performed on an Agilent Series 1260 system (Agilent Technologies, Santa Clara, CA, USA), equipped with a vacuum degasser, quaternary pump, autosampler, column compartment, and evaporative light-scattering detector, controlled by Agilent 1260 LC Software (OpenLab chemstation C. 01. 07, Santa Clara, CA, USA). A Zorbax Eclipse XDB-C18 column $\left(250 \mathrm{~mm} \times 4.6 \mathrm{~mm}, 5 \mu \mathrm{m}\right.$ particle size) was used for chromatography at $30^{\circ} \mathrm{C}$. Gradient elution was conducted with (A) water and (B) acetonitrile as mobile phases. The gradient was as follows: 0-15 min, $15-21 \%$ B; 15-37 min, 21-23\% B; 37-52 min, 23-24\% B; 52-65 min, 24-26\% B; 65-70 min, 26-100\% B; $70-75 \mathrm{~min}, 100-15 \% \mathrm{~B} ; 75-85 \mathrm{~min}, 15-15 \% \mathrm{~B}$. The flow rate was $1.0 \mathrm{~mL} / \mathrm{min}$, the sample injection volume was $30 \mu \mathrm{L}$, and the column temperature was $35^{\circ} \mathrm{C}$. HPLC-ELSD was to detection of 8 saponins with a gas spray nebulizer temperature of $50{ }^{\circ} \mathrm{C}$, drift tube temperature of $85^{\circ} \mathrm{C}, \mathrm{N}_{2}$ gas pressure of 55 psi.

\subsection{Method Validation of the Quantitative Analysis}

Six replicates of the same sample were collected for the repeatability validation of the processing method of the sample solution. The method's precision was validated by injecting the same sample solution six times. The stability of samples solutions was analyzed at 1, 2, 4, 8, 12, and $24 \mathrm{~h}$ after their preparation. To determine the recovery of the method, eight mixed standard solutions of saponin were added to the six samples by the same method as the sample-solution processing. The standards (deapioplatycoside E $4.30 \mathrm{mg}$, platycoside E $5.00 \mathrm{mg}$, deapioplatycodin $\mathrm{D}_{3} 2.30 \mathrm{mg}$, platycodin $\mathrm{D}_{3}$ $3.77 \mathrm{mg}$, deapioplatycodin $\mathrm{D} 1.78 \mathrm{mg}$, platycodin $\mathrm{D}_{2} 2.10 \mathrm{mg}$, platycodin $\mathrm{D} 8.00 \mathrm{mg}$, polygalacin $\mathrm{D}$

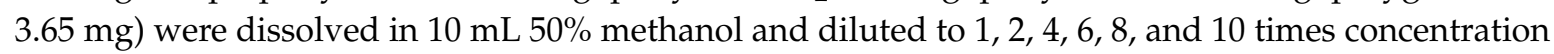
to establish the standard curve for calibration. The sample injection volume was $30 \mu \mathrm{L}$.

\subsection{Fingerprint Analysis}

The fingerprint analysis of all samples was performed by HPLC-UV method. Equal amount of powder $(1.0 \mathrm{~g})$ from each origin was used as the sample for fingerprint analysis. Gradient elution system was conducted with (A) $0.1 \%$ phosphoric acid and (B) acetonitrile as mobile phases. The gradients were as follows: 0-23 $\mathrm{min}, 15-15 \% \mathrm{~B} ; 23-45 \mathrm{~min}, 15-21 \% \mathrm{~B} ; 45-55 \mathrm{~min}, 21-23 \% \mathrm{~B} ; 55-80 \mathrm{~min}, 23-25 \% \mathrm{~B}$; 80-100 $\mathrm{min}$, and $25-35 \% \mathrm{~B}$. The flow rate was $0.8 \mathrm{~mL} / \mathrm{min}$, the sample injection volume was $20 \mu \mathrm{L}$, the column temperature was $30^{\circ} \mathrm{C}$, and the detection wavelength was $210 \mathrm{~nm}$ [23].

\subsection{Data Analysis}

HCA and PCA were performed by using SPSS 20.0 (SPSS Inc., Chicago, IL, USA). The 8 saponins contents of PR samples from 11 provinces were determined in order to differentiate and classify PR samples of various origins. These data were standardized before HCA and PCA. First and second principal components were selected to draw a scatter plot for PCA. The average linkage between 
groups method was applied for HCA, with square euclidean distance used to measure the distance matrix between observations [24].

Nineteen characteristic peaks in the chromatograms were selected. The reference fingerprint and similarity among tested samples were calculated and generated by a Similarity Evaluation System for Chromatographic Fingerprint of Traditional Chinese Medicine (Version 2004A, Chinese Pharmacopoeia Commission, Beijing, China) software, which was recommended by the State Pharmacopoeia Commission of the People's Republic of China [25].

\section{Conclusions}

In this paper, a rapid and reliable HPLC-ELSD method was developed for the simultaneous determination of 8 saponins contents and chromatographic fingerprint analysis was performed to evaluate the quality of PR samples from various origins in China. The samples with the highest saponins contents were from southern China. All samples in the 11 provinces of China were classified into four groups based on their contents of 8 saponins using hierarchical clustering method. The resulting classification was closely associated to the geographical environment of the regions.

Supplementary Materials: The following are available, Table S1: Contents $(\mathrm{mg} / \mathrm{g})$ of 8 types of saponins in 89 samples.

Author Contributions: S.G. and H.P. conceived and designed the experiments; H.L. performed the experiments and wrote the manuscript; M.J., S.C., T.X., Y.H. and Q.C. analyzed the data; All authors read and approved the final manuscript.

Funding: This study was supported by the Scientific and Technological Project of Anhui Province (15011d04005).

Conflicts of Interest: The authors declare no conflict of interest.

\section{References}

1. Zhao, X.L. Research progress in chemical constituents, biological activities and exploration utilization of Platycodon grandiflorum. China Condiment 2012, 37, 5-8.

2. Yoo, D.S.; Choi, Y.H.; Cha, M.R.; Lee, B.H.; Kim, S.J.; Yon, G.H.; Hong, K.S.; Jang, Y.S.; Jang, Y.S.; Lee, H.S.; et al. HPLC-ELSD analysis of 18 platycosides from balloon flower roots (Platycodi Radix) sourced from various regions in Korea and geographical clustering of the cultivation areas. Food Chem. 2011, 129, 645-651. [CrossRef]

3. Nyakudya, E.; Jeong, J.H.; Lee, N.K.; Jeong, Y.S. Platycosides from the roots of Platycodon grandiflorum and their health benefits. Prev. Nutr. Food Sci. 2014, 19, 59-68. [CrossRef] [PubMed]

4. Lu, H.Y.; Peng, H.S.; Gui, S.Y.; Peng, D.Y. Evolution and transition of quality evaluation of Platycodon grandiflorum. China J. Chin. Mater. Med. 2017, 42, 1637-1640.

5. Zhang, L.; Wang, Y.; Yang, D.; Zhang, C.; Zhang, N.; Li, M.; Liu, Y. Platycodon grandiflorus-An ethnopharmacological, phytochemical and pharmacological review. J. Ethnopharmacol. 2015, 164, $147-161$. [CrossRef] [PubMed]

6. Wang, C.Z.; Zhang, N.Q.; Wang, Z.Z.; Qi, Z.; Zhu, H.L.; Zheng, B.Z.; Li, P.Y.; Liu, J.P. Nontargeted metabolomic analysis of four different parts of Platycodon grandiflorum grown in northeast China. Molecules 2017, 22, 1280. [CrossRef] [PubMed]

7. Choi, Y.H.; Yoo, D.S.; Choi, C.W.; Cha, M.R.; Kim, Y.S.; Lee, H.S.; Lee, K.R.; Ryu, S.Y. Platyconic acid A, a genuine triterpenoid saponin from the roots of Platycodon grandiflorum. Molecules 2008, 13, 2871-2879. [CrossRef] [PubMed]

8. Lee, J.W.; Ji, S.H.; Kim, G.S.; Song, K.S.; Um, Y.; Lim, O.T.; Lee, Y.; Hong, C.P.; Shin, D.H.; Kim, C.K.; et al. Global profiling of various metabolites in Platycodon grandiflorum by UPLC-QTOF/MS. Int. J. Mol. Sci. 2015, 16, 26786-26796. [CrossRef] [PubMed]

9. He, M.; Li, Y.P.; Yan, J.; Cao, D.S.; Liang, Y.Z. Analysis of essential oils and fatty acids from Platycodi Radix using chemometric methods and retention indices. J. Chromatogr. Sci. 2013, 51, 318-330. [CrossRef] [PubMed] 
10. Choi, J.H.; Jin, S.W.; Choi, C.Y.; Kim, H.G.; Kim, S.J.; Lee, H.S.; Chung, Y.C.; Kim, E.J.; Lee, Y.C.; Jeong, H.G. Saponins from the roots of Platycodon grandiflorum ameliorate high fat diet-induced non-alcoholic steatohepatitis. Biomed. Pharmacother. 2017, 86, 205-212. [CrossRef] [PubMed]

11. Yuk, T.; Sung, J.; Han, H.M.; Kim, Y.; Jeong, H.S.; Lee, J. Effect of different cooking methods on phytochemical content and antioxidant capacity of Platycodon grandiflorum root. Food Sci. Biotechnol. 2015, 24, 1597-1602. [CrossRef]

12. Chun, J.; Ha, I.J.; Kim, Y.S. Antiproliferative and apoptotic activities of triterpenoid saponins from the roots of Platycodon grandiflorum and their structure-activity relationships. Planta Med. 2013, 79, 639-645. [CrossRef] [PubMed]

13. Jang, K.J.; Kim, H.K.; Han, M.H.; Oh, Y.N.; Yoon, H.M.; Chung, Y.H.; Kim, G.Y.; Hwang, H.J.; Kim, B.W.; Choi, Y.H. Anti-inflammatory effects of saponins derived from the roots of Platycodon grandiflorus in lipopolysaccharide-stimulated BV2 microglial cells. Int. J. Mol. Med. 2013, 31, 1357-1366. [CrossRef] [PubMed]

14. Sun, L.L.; Wang, M.; Zhang, H.J.; Liu, Y.N.; Ren, X.L.; Deng, Y.R.; Qi, A.D. Comprehensive analysis of Polygoni Multiflori Radix of different geographical origins using ultra-high-performance liquid chromatography fingerprints and multivariate chemometric methods. J. Food Drug Anal. 2018, 26, 90-99. [CrossRef] [PubMed]

15. Liu, Z.H.; Wang, D.M.; Li, D.W.; Zhang, S. Quality evaluation of Juniperus rigida Sieb. et Zucc. Based on phenolic profiles, bioactivity, and HPLC fingerprint combined with chemometrics. Front. Pharmacol. 2017, 8, 198. [CrossRef] [PubMed]

16. Ha, Y.W.; Na, Y.C.; Seo, J.J.; Kim, S.N.; Linhardt, R.J.; Kim, Y.S. Qualitative and quantitative determination of ten major saponins in Platycodi Radix by high performance liquid chromatography with evaporative light scattering detection and mass spectrometry. J. Chromatogr. A 2006, 1135, 27-35. [CrossRef] [PubMed]

17. Ma, C.M.; Sun, Z.; Chen, C.B.; Zhang, L.L.; Zhu, S.H. Simultaneous separation and determination of fructose, sorbitol, glucose and sucrose in fruits by HPLC-ELSD. Food Chem. 2014, 145, 784-788. [CrossRef] [PubMed]

18. Jin, C.S.; Zhang, W.; Gui, S.Y. Determination of the content of platycodin-D and platycodinpolysaccharides in radix platycodonis from different sources. Anhui Med. Pharm. J. 2014, 18, 246-249.

19. Li, X.F.; Du, Y.F.; Xie, X.N.; Liu, S.M.; Hao, Z. HPLC fingerprints of Platycodon grandiflorum from different habitats and the determination of platycodin-D. Chin. Tradit. Pat. Med. 2010, 32, 529-532.

20. Yu, S.; Zhu, L.; Xiao, Z.G.; Shen, G.; Li, J.; Lai, H.S.; Li, J.J.; Chen, H.B.; Zhao, Z.Z.; Yi, T. Rapid fingerprint analysis of Flos Carthami by ultra-performance liquid chromatography and similarity evaluation. J. Chromatogr. Sci. 2016, 54, 1619-1624. [CrossRef] [PubMed]

21. Sabir, A.; Rafi, M.; Darusman, L.K. Discrimination of red and white rice bran from Indonesia using HPLC fingerprint analysis combined with chemometrics. Food Chem. 2017, 221, 1717-1722. [CrossRef] [PubMed]

22. Chu, S.S.; Tan, L.L.; Liu, C.C.; Peng, H.S.; Duan, H.Y.; Huang, L.Q. Growth rings in roots of medicinal perennial dicotyledonous herbs from temperate and subtropical zones in China. Microsc. Res. Tech. 2018, 81, 365-375. [CrossRef] [PubMed]

23. Ge, D.; Wang, J.T.; Gui, S.Y.; Qu, H.F. A Research about comparison between different harvest period of platycodonis radix chemical composition by fingerprint of Traditional Chinese Medicine. Lishizhen Med. Mater. Med. Res. 2017, 28, 217-219.

24. Aga, E.B.; Nie, L.J.; Dongzhi, Z.M.; Wang, J.L. Multi-component quantitative analysis combined with chromatographic fingerprint for quality assessment of Onosma hookeri. China J. Chin. Mater. Med. 2015, 40, 4442-4445.

25. Wu, Y.B.; Zheng, L.J.; Yi, J.; Wu, J.G.; Chen, T.Q.; Wu, J.Z. Quantitative and chemical fingerprint analysis for the quality evaluation of Receptaculum Nelumbinis by RP-HPLC coupled with hierarchical clustering analysis. Int. J. Mol. Sci. 2013, 14, 1999-2010. [CrossRef] [PubMed]

Sample Availability: Samples of the compounds are available from the authors. 